\title{
Effective Orientation Strategies for Student Athletes Participating in NCAA Division III and NAIA Football Programs
}

\author{
Dr. Richard E. Newman and Dr. Michael T. Miller
}

The orientation of new students to the college environment establishes the foundation for the entire college experience. The skills taught, the attitudes conveyed, and the institutional expectations outlined in orientation programs help incoming students set and build internalized, personal parameters for how they will approach college life. Twale (1989) noted that the orientation process for new students both sets the academic expectations for the entire college experience and builds an espirit de corps among entering students. The transition of new students to college is clearly an important dimension of institutional programming, and an activity that should be undertaken with a high degree of intentional behavior, planning, and execution (Nadler \& Miller, 1999).

The identification of institutional expectations is especially important for student-athletes (Pope, 1997). Although the entire college experience ultimately frames an attitude toward life and achieving personal success, the initial experiences of student-athletes, particularly in football and basketball, are vital to convey a holistic sense of college expectations, academic integrity, and rule compliance (Newman, 1994).

The transition of student-athletes to college is relatively unexplored and not well profiled. Perhaps the most well-known academic program for student-athletes is the Challenging Athletes Minds for Personal Success (CHAMPS)/Life Skills program that was launched by the National Collegiate Athletic Association (NCAA) in 1994. The program's goal was to improve the quality of the student-athlete's experience in college (NCAA, 1999). Despite the popularity of the CHAMPS/Life Skills program and several case studies of institutions reporting how they develop and provide orientation programs for student-athletes, there are virtually no established foundations for providing services to student-athletes, particularly in the high-risk sports of football and basketball.

Major college football and basketball programs have certainly been the most popular athletic areas to be widely criticized by both the general public and the academic community (Dempsey, 2001; French, 2001). In fact, Selingo (2003) reported in the Chronicle of Higher Education that a majority of the public does not support what has come to be called the "college athletic arms race". This supported the dominant theme of Knapp, Rasmussen, and Barnhart (2001) who identified a high level of skepticism about the integrity of student-athletes by fellow students. Well documented scandals in football and basketball include academic misconduct, illegal drug use, violating regulations for training and recruiting, point shaving, and even a bevy of unethical behaviors and attitude by college coaches themselves (Gerdy, 2001).

Dr. Richard Newman is an Associate Professor and Chair of the Department of Physical Education at Presbyterian College in Clinton, South Carolina. Dr. Michael Miller is an Associate Professor of Higher Education Leadership at the University of Arkansas in Fayetteville, Arkansas. 
Although rule violations are abundant in the largest division of college sports, NCAA Division I, there are fewer reported in the smallest NCAA division for football and basketball, Division III (Naughton, 1997). There are over 400 colleges and universities that participate in NCAA Division III, ranging from small, church affiliated colleges to larger, nationally recognized universities. These athletic programs are not allowed to offer scholarships, and are often identified as the model that higher education should aspire to, where student-athletes are predominantly enrolled for academic pursuits and have a distinct separation from a sport in the "off-season."

Using the notion of NCAA Division III athletics as an example, the current study was designed to identify effective activities to provide a well-rounded orientation for incoming athletes, specifically football players, to campus. The study specifically focused on the effectiveness of orientation activities, and was designed to be exploratory in nature. Football players were selected for three distinct reasons: (1) there are more student-athletes involved in football than in any other single college sport; (2) football represents a sport that has had many difficulties with rules violations in other NCAA divisions; and (3) there is the greatest potential to impact a larger culture by working with such a high visibility sport.

\section{Orientation of Student-Athletes}

Some form of new student orientation program is in place at virtually every college and university in America, and these programs are broad in scope. However, they are typically based on the type of student enrolled and the intended function of orientation (Mullendore, 1992). For example, orientation programs in community colleges are often designed to be short, highly functional introductions to the business of enrolling, registering, and paying fees. At some residential universities, the focus is on team-development and fostering opportunities for creating a social support network through week-long programs that even encompass parents.

Although there is no "one size fits all" model for orientation, the Council for the Advancement of Standards (CAS) has issued a set of guidelines for new student orientation. Called the Standards for New Student Orientation, these suggested landmarks have been in place since the 1980s (CAS, 1988) and offer some general guidance for what should be included in an orientation offering. Among the 20 key elements identified are such recommendations as developing relationships between new students and continuing students, faculty, staff, administrators, and even campus neighbors. CAS recommends some degree of training for personal safety, how to handle the business affairs of campus enrollment, and creating support networks among new students. These standards have been widely distributed and have even been used as criteria to evaluate orientation programs (Nadler \& Miller, 1997). This series of orientation assessments, headed by Nadler, have included segmentation by race, gender, major, and even age.

Pope (1997), among others, has argued that student-athletes possess unique needs and, in fact, templates of activities such as orientation must be modified to fit the student-athlete mindset. He noted that student-athletes often select an institution based 
on opportunity to participate in athletics, especially when receiving a scholarship, so these students view themselves as athletes first and students second. This thinking is the result of not only a personal desire to participate in athletics, but also is the result of institutional pressure to succeed on the playing field (Miller \& Kerr, 2002). College football is perhaps one of the most obvious visual public displays of pressure to perform athletically (Newman, 1994). These student-athletes are expected to arrive on campus before the regular semester begins, participate in all aspects of football life throughout the season, including diet monitoring, required and implied participation in strength and conditioning exercises, film study, formal and informal practices, and largely to protect eligibility, required study hall. In the off-season for football, again, just as an example, these same players can not be required to participate in strategy or technique training, film study, and strength and conditioning, but it is highly "recommended." In fact, summer participation in strength and conditioning is approached with a near required attitude, as coaches respond that participation in summer strength and conditioning is indeed voluntary, but so is participation on the team.

If orientation for new students is indeed an opportunity to teach about priorities and intellectual expectations, then as Pope alluded, there is a significant need to work with student-athletes. And although football may represent an extreme, similar expectations are seen in virtually all sports, ranging from basketball, softball, and baseball to swimming, track and field, and volleyball. Orientation programs that will be successful will be those that incorporate realistic expectations and have a high-level of acceptance from coaches and athletic administrators.

Orientation programs for student-athletes are often coordinated by academic support centers or offices and are based on short, information-intense programs that involve highly technical information, such as who to contact with certain questions, provides advising and/or course selection, and so on. Many institutions have also moved to peer mentor programs, with mentors being selected within the same sport, and required NCAA rules compliance classes. The expectation has increasingly led to the direction of a managed life in college, with limited personal decision-making.

The other popular model for orientating student-athletes is similar to mainstreaming, that is, student-athletes are immersed in the mainstream culture of the institution. All student-athletes are registered and participate in the institution's orientation with the thinking that this will allow student-athletes to become familiar with campus life in general and to be more self-sufficient in making decisions. This model is more popular with non-Division I athletic programs where there is less attention on revenue generation from all sports.

NCAA Division III and NAIA college football are something of a paradox for college sports. These programs do provide a substantial amount of publicity when they are successful, yet there is rarely any revenue generation. Student-athletes are indeed recruited, but they are not provided any financial aid or minimal financial aid in the case of NAIA participation for playing the sport. The majority of institutions have outstanding academic reputations and are considered moderate to highly selective. Institutions compete regionally, typically ride buses to games, and feel the same 
intensity, joy, pain, elation, and fulfillment that athletes do at other levels of competition. These student-athletes also mirror their institution's demographic profile, with a large percentage of upper-middle income families providing support for tuition and fees for these students.

NCAA Division III and NAIA football programs are also replete with their own heritage, traditions, rivalries, and scandals. Murphy (2002) and Moore (2000) have both catalogued some of this tradition in their two books, and there is even a website devoted to NCAA Division III football (www.D3football.com). The success that these programs have had may well hold a powerful solution to addressing some of the problems associated with athletics at other levels of competition. Although the current study is exploratory, it does hold the potential to identify some of the insights associated with student-athlete success and coaching and mentoring philosophies.

\section{Research Procedures}

As an exploratory study, a three-round Delphi procedure was utilized. This survey method allows for the identification of consensus from a panel of geographically separated experts. For the purpose of the current study, the panel of experts was identified as current NCAA Division III and NAIA football coaches.

A panel of coaches who were identified as effective in working with student-athletes nominated other coaches until a slate of 50 coaches were identified. A mailing asking each coach to participate was mailed in the winter of 2002-2003 until a pool of 30 coaches were identified who agreed to participate in all three rounds of the study in the spring of 2003. The decision was made not to include more than 30 coaches for technical reasons and the traditional use of the Delphi survey with smaller sample sizes.

Coaches were initially asked to identify up to five activities that they employ that are effective in providing a well-rounded orientation for new football players to campus. A total of 26 coaches responded to the first round and all remaining rounds of the data collection, and after editing for duplication, 27 strategies or activities were rated by the coaches in the second round of the survey.

For the third round of the survey, coaches were provided their individual rating of each item as well as the group mean and range for each activity. The coaches were then asked to re-consider each activity and its degree of possible effectiveness for providing a well-rounded orientation for new football players, and re-evaluate each activity.

\section{Findings}

A total of 26 coaches from NCAA Division III (23) and NAIA (3) football programs participated in all three rounds of the exploratory Delphi study. Overall, the 27 strategies for effective orientation were provided a grand mean rating of 3.64 (neutral, indicating that this strategy might or might not be effective) in the second round of rating. The 26 coaches made a total of 165 changes to their round two ratings after considering group data in round three, for an average of 6 rating changes per coach. The overall agreement mean rating for the items decreased to 3.48 (also in the 'neutral' range on the 1-to-5 
Likert-type scale). Almost a quarter of the orientation strategies $(22 \%$; $n=6)$ had a final agreement mean rating between 4 and 5 , indicating that the strategy would be somewhere between 'probably effective' and 'definitely effective.' Nearly the same number $(18 \% ; n=5)$ had final agreement mean ratings between 2 and 3 (that is, between 'not effective' and 'neutral'). The majority $(59 \% ; n=16)$ of strategies identified had final agreement mean ratings between 3 and 4 ('neutral' to 'probably effective').

The orientation strategies perceived to be the strongest were those that focused on peer-relationships and team group behavior. In a sense, these strategies or activities suggested the importance of developing a group norm, and emphasized an acceptable or superior norm in terms of behavior and expectation. Using upper-class student-athletes, coaches are able to identify desirable traits and habits and reinforce them throughout a team environment by having them 'taught' through peer mentoring scenarios. The strategy of having a group of upper-class players meet with newcomers during pre-season to stress the importance of academics and education (mean 4.53; SD .760), having upper-class players meet with freshman multiple times throughout the year to stress responsible living (mean 4.30, SD .735), using a buddy system (mean 4.15, SD .674), and simply utilizing team building activities (mean 4.11, SD .652) were the most agreed upon set of orientation program strategies that can be effective.

Conversely, the elements of an orientation program perceived to be the least effective were the five strategies or orientation activities that were rated between 2.0 (disagree that the measure would be effective) and 3.0 (neutral perceptions). These orientation program elements included learning the college's fight song (mean 2.88; SD 1.24 ) and alma mater (mean 2.46; SD 1.06), dividing the team into 'huddles' to discuss issues each day (mean 2.57; SD .856), having a speaker be part of orientation to discuss date-rape (mean 2.57; SD .856), and having the team meet informally with the mayor, police chief, and sheriff so that each see the good sides of each other (mean 2.19; SD 1.02).

\section{Disc ussion}

Effective orientation strategies continue to be one of the strongest foundations for increasing student retention and improving student satisfaction with the collegiate experience. Orientation programs have also consistently evolved to reflect differences in institutional culture and demands, and have been elongated to include programs in the second semester of college and even through a full second year of college. Aggressive enrollment management programs also consider peer-mentoring from both the mentor and the student being mentored, that is, benefiting from the wisdom of a more senior student who has had perhaps a wider variety of experiences, and then the personal investment of the mentor, and the residual benefits of having a more senior student think critically about how to navigate college and what to advise another to do. Athletic programs have some similarities in that they typically develop team-focused or strong group dynamics by encouraging or forcing students to spend large amounts of time together. Whether this investment of time is structured enough (outside of basic parameters such as study table or compliance class) and considered from the perspective 
of increasing positive performance (continued enrollment) is certainly an area ripe for further research.

The ideals of non-scholarship football programs are only marginally reflected in the strategies and activities identified by the participating coaches. Generally, the activities they identified, and specifically those which they agreed with, are universal elements that have application across all different types or divisions of college sports. There are some unique strategies that were identified, though, that do begin to distill something different and unique about the non-scholarship environment reflected in NCAA Division III and NAIA football. First, having the college president stress an institutional mission (mean 3.76) is actually a strong indication that these football players could be considered or are special on some level by having individual access to the institution's president, but it also indicates that the coaches and administrators working with the football program recognize that these are students first who are there for an education.

The second and other area that differentiates NCAA Division III and NAIA football from other divisions was the lack of attention on the behavioral difficulties that have become headlines in, particularly, Division I athletic programs. Participating coaches did not see great value in worrying about how these non-scholarship athletes interact with the police or sheriff, were less concerned about date-rape being a problem with these athletes, and they gave only moderate support (mean 3.57) to focusing on drug and alcohol issues.

In terms of personnel involvement, coaches were mostly self-reliant, identifying only one strategy that involved faculty, one that involved boosters, two that involved a dean or vice president for student affairs, and two strategies that involved the college's president. Conversely, coaches suggested their involvement in orientation in three strategies, but relied heavily on other students in the football program to transition new players into the program and the institution in no less than eight orientation activities. The reliance on fellow students to provide an orientation for new football players made use of such activities as a buddy system (peer-mentoring), upper-class students mentoring new students, focusing on team building and socialization, and even studying together at mandatory study halls.

The relatively limited breadth of ideas and strategies used by college coaches also suggests that they might want to partner with orientation professionals to review the process of transition and acculturation into an institution with specific expectations for performance as a football player. Additionally, orientation professionals might want to consider what kinds of orientation strategies and activities work best with students who enroll for involvement in a specific activity. Work with these students, who also include highly specialized or special interest students (competitive in forensics and band members for example) could also prove to be a valuable area for identifying meaningful orientation strategies and in understanding the group dynamics related to performance on the field and in the classroom by football players. These types of questions will naturally lead to classifying and developing perhaps psychological stages (such as those by Tinto or Chickering) of student development specifically related to student-athletes, with a strong probable correlation between the intensity of a program and the exhibition of certain psychological stages. 
What these findings also reveal is that NCAA Division III and NAIA football programs have not become as commercialized and structured as in NCAA Division I. There remains a great span of differential behavior among programs, often predicated on coaching behaviors, experiences, and expectations. In a sense, the NCAA Division III or NAIA coach is a much more central figure in the success or failure of a football program than in other divisions.

As indicated earlier, this initial investigation was intended to be an exploratory start to a better understanding of non-scholarship athletics in the hopes of finding perhaps a model for intercollegiate athletics that is more attuned to the unique nature of higher education. The study does point in a direction for more research and dissemination in this area, but perhaps more important, suggests that professionals in athletics, student affairs, and academic affairs all need to be in meaningful communication that promotes the welfare of students.

\section{References}

Council for the Advancement of Standards. (1988). Standards for new student orientation. Washington: Author.

Dempsey, C. (2001). College sports under siege! What's new? Professional Ethics: A Multidisciplinary Journal, 9(2), 23-30.

French, P. A. (2001). Ethics, intercollegiate sports, and the mission of the university. Professional Ethics: A Multidisciplinary Journal, 9(2), 11-21.

Gerdy, J. R. (2001). Have college athletics become destructive in America? Professional Ethics: A Multidisciplinary Journal, 9(2), 67-78.

Knapp, T., Rasmussen, L., \& Barnhart, R. (2001). What college students say about intercollegiate athletics: A survey of attitudes and beliefs. College Student Journal, 35, 96-100.

Miller, P. S., \& Kerr, G. (2002). The athletic, academic, and social experiences of intercollegiate student-athletes. Journal of Sports Behavior, 25, 346-368.

Murphy, A. (2002). The sweet season: Football, family, and a bit of faith at Minnesota's St. John's University. New York: Perennial/Harper Collins.

Moore, J. (2000). Tales from the small time: A celebration of small college athletics. Orange, CA: Chapman University.

Mullendore, R. H. (1992). Student based programming in orientation. In D. P. Nadler (Ed.), Orientation Director's Manual (pp. 43-52). Statesboro, GA: National Orientation Director's Association.

Nadler, D., \& Miller, M. (1999). Designing transitional programs to meet the needs of multi-ethnic first year students. Journal of College Orientation and Transition, 6(2), 20-27.

Nadler, D., \& Miller, M. (1997). Student satisfaction with orientation: A program assessment and cultural stratification. Journal of College Orientation and Transition, 5(1), 7-14. 
National Collegiate Athletic Association. (1999). NCAA CHAMPS/Life skills program. Indianapolis, IN: Author.

Naughton, J. (1997). In division III, college sports thrive with few fans and even fewer scandals. Chronicle of Higher Education, 44(13), 41-42.

Newman, R. E. (1994). Attitudes of high school personnel toward NCAA academic integrity reform measures and proposals. Unpublished doctoral dissertation, University of Nebraska-Lincoln.

Pope, M. (1997). An analysis of the perceptions of athletic department and student affairs office personnel regarding academic support services provided to studentathletes. Unpublished doctoral dissertation, University of Alabama, Tuscaloosa.

Robst, J., \& Keil, J. The relationship between athletic participation and academic performance: Evidence from division III. Applied Economics, 32(5), 547.

Selingo, J. (2003). What Americans think about higher education. Chronicle of Higher Education, 49(34), A 10.

Twale, D. (1989). Social and academic development in freshman orientation: A time frame. NASPA Journal, 27, 160-167. 
Effective Orientation Strategies and Activities

\begin{tabular}{|c|c|c|c|c|}
\hline Orientation Activity & Mean & SD & Min & $\operatorname{Max}$ \\
\hline $\begin{array}{l}\text { Group of upperclass players meet } \\
\text { with newcomers during } \\
\text { pre-season to stress the } \\
\text { importance of academics and } \\
\text { education }\end{array}$ & 4.53 & .760 & 3 & 5 \\
\hline $\begin{array}{l}\text { Group of upperclass players meet } \\
\text { with freshman multiple times } \\
\text { throughout the year } \\
\text { to stress responsible living }\end{array}$ & 4.30 & .735 & 3 & 5 \\
\hline $\begin{array}{l}\text { The buddy system (frosh paired } \\
\text { with upperclassman) during } \\
\text { two-a-days }\end{array}$ & 4.15 & .674 & 3 & 5 \\
\hline $\begin{array}{l}\text { Team building activity for } \\
\text { entire team }\end{array}$ & 4.11 & .652 & 3 & 5 \\
\hline College president addresses team & 4.07 & .627 & 3 & 5 \\
\hline $\begin{array}{l}\text { Special practices for new } \\
\text { players only allowing for a } \\
\text { pace of practice that is } \\
\text { comfortable for newcomers }\end{array}$ & 4.07 & 1.41 & 1 & 5 \\
\hline $\begin{array}{l}\text { Individual meetings with } \\
\text { players and coaches }\end{array}$ & 3.96 & .958 & 2 & 5 \\
\hline Rely on institutional orientation & 3.92 & .744 & 3 & 5 \\
\hline $\begin{array}{l}\text { Big brother program (frosh paired } \\
\text { with older players) throughout } \\
\text { academic career }\end{array}$ & 3.88 & .652 & 3 & 5 \\
\hline $\begin{array}{l}\text { College president stresses } \\
\text { college mission }\end{array}$ & 3.76 & 1.27 & 1 & 5 \\
\hline $\begin{array}{l}\text { Seniors help freshman check-in } \\
\text { to residence halls }\end{array}$ & 3.73 & .724 & 3 & 5 \\
\hline $\begin{array}{l}\text { Vice president for student affairs } \\
\text { offers advice on campus life } \\
\text { and behavior }\end{array}$ & 3.69 & .735 & 2 & 4 \\
\hline
\end{tabular}




\section{Orientation Activity}

Special speaker on drug and alcohol awareness

Rely on institutional facultystudent mentoring program

Cook-out for players, coaches, and families to get to know each other

Lunch with boosters to discuss life and school issues

One member of the coaching staff is assigned to a class of students

Vice president for student affairs speaks to incoming freshmen

Weekly grade reports between an advisor and the football player

Special class ('insights') for new players that meets once a week for five weeks to talk

New players are introduced at a lunch to key personnel from campus

Mandatory study table monitored by seniors

All players learn the college fight song

Team is divided into 'huddles' to talk each day about issues and events

Special speaker on date rape

All players learn the college alma mater

3.57

3.46

3.26

3.26

3.00

3.00

2.73

2.46
Mean

SD

Min

$\operatorname{Max}$

1.02

2

5

.752

3

5

.904

2

4

.891

2

4

1.07

4

1.07

2

5

.800

2

4

.565

2

4

1.24

4

.724

2

4 .856

4

1.066

4 
Orientation Activity

Team meets informally with the mayor, police, and sheriff so that both get to see the good sides of each other.
Mean

SD

Min

$\operatorname{Max}$

2.19

1.02

1

4 